\title{
Characterization of Inversions as a Type of Structural Chromosome Aberration
}

\author{
B. Muss and G. Schwanitz* \\ Institute of Human Genetics, University of Bonn, Wilhelmstrasse 31, \\ D-53111 Bonn, Germany
}

KEYWORDS Pericentric inversions; paracentric inversions; comparison of euchromatic and heterochromatic
rearrangements; inversion hotspots

ABSTRACT Inversions comprise approximately $10 \%$ of structural aberrations, with pericentric inversions clearly outnumbering paracentric rearrangements (66\% as compared to $34 \%$ ), due in part to diagnostic difficulties in the latter group. At $11 \%$, chromosome 2 displays the highest recombination frequency for euchromatic pericentric inversions, while chromosomes 3 and 7 are most often involved in paracentric inversions (16\% and 19\%, respectively). Inversions of the constitutive heterochromatin are far more frequent than those involving the euchromatin, totalling $20 \%$ for only 6 chromosomes. Chromosome 4 demonstrates the highest frequency of pericentric inversions (15\%). The genetic risks for inversion carriers differ significantly depending on the chromosome involved and on the specific inverted region, ranging from less than $1 \%$ to a maximum of $30 \%$. Cryptic inversions resulting in a microdeletion in chromosome 7q11.23 have been demonstrated to be causative in 33\% of Williams-Beuren cases, apparently due to an abnormal course of meiosis I. Molecular cytogenetic investigations of the parents of carriers of cryptic chromosome aberrations may be expected to detect a higher frequency of paracentric inversions than has thus far been demonstrated.

\section{INTRODUCTION}

An inversion is a structural aberration of the chromosomes which results from an intrachromosomal break and subsequent rearrangement. Two break events take place in the chromosome, and the segment which lies between the two breakpoints is rotated by $180^{\circ}$ and re-inserted into the chromosome.

The newly rearranged chromosome now consists of an inverted segment and two flanking, distal, non-inverted regions. The majority of carriers of chromosomal inversions are phenotypically normal, both in the heterozygous and in the rare homozygous state. Homozygosity is usually found only in offspring of consanguineous parents or in geographically or culturally isolated regions. Apparently, the function of the genetic material remains unaffected, as long as there is no change in the amount of genetic material. Thus, this type of structural rearrangement can be termed balanced. However, the rearrangement may disrupt genes or segments of the chromosome may be deleted

Corresponding author: Prof. Dr. Gesa Schwanitz, Institute of Human Genetics, University of Bonn Wilhelmstrasse 31, D-53111 Bonn, Germany Tel.L +49 228 287-22338,

Fax: +49 228 287-22380

E-mail: gesa.schwanitz@ukb.uni-bonn.de or duplicated, thus changing the total quantity or the function of the genetic material. This type of rearrangement is termed unbalanced and the carrier of such an aberration will be phenotypically abnormal.

In complex inversions, other rearrangements of the same chromosome, such as translocations, occur in combination with the inversion. In contrast, the inversion constitutes the only structural aberration in carriers of single inversions.

Inversions are differentiated according to the position of the centromere relative to the inverted segment and are termed either pericentric or paracentric. These will be discussed in more detail in the following sections.

Inversions are most likely to occur during meiosis. Investigations of mosaics in $\mathrm{C}$ band polymorphisms have demonstrated that a postzygotic origin may also be possible, caused by somatic crossing-over as has been shown in various investigations (Miller and Therman 2001).

The majority of studies focus on pericentric inversions, as a sufficient number of cases to allow precise quantitative research exists only for this type of rearrangement. As a result, the information given here will primarily refer to findings reported for pericentric inversions. Differences as compared to paracentric inversions will be discussed specifically later.

A differentiation between paracentric and 
pericentric inversions is of particular importance for a precise assessment of genetic risks resulting from abnormal pairing of chromosomes during meiosis, as these differ greatly for the two types of aberrations.

The key difference between euchromatic and heterochromatic inversions is in their respective ability to cause an abnormal phenotype. On the one hand, rearrangements of the heterochromatin represent variants of the normal phenotype, and they are never associated with phenotypic aberrations or an increased genetic risk. Euchromatic inversions, on the other hand, occur in genetically relevant segments of the chromosome and can thus cause phenotypic abnormalities if the breakpoints disrupt a gene or if they occur in an unbalanced form. An inversion in the X chromosome, for example, is responsible for approximately half of all cases of haemophilia A. Sequence repetitions promoting the occurrence of an inversion are located both within and just outside of the gene coding for factor VIII, part of the blood clotting cascade.

\section{REARRANGEMENTS WITHIN THE EUCHROMATIN}

\section{Pericentric Inversions}

\section{Inversions of the Autosomes}

In this type of inversion the centromere is located within the inverted region. If the two breakpoints are not equally far from the centromere, then the inversion will change the position of the centromere in the recombinant chromosome, resulting in an altered centromere index. Thus, a submetacentric chromosome may turn into a metacentric chromosome and vice versa. If the breakpoints are equidistant from the centromere, its position remains unchanged. However, a structural rearrangement has taken place that, unless the inverted segment comprises only one band, will be apparent in an altered banding pattern.

\section{Unbalanced Rearrangements Resulting from Gene Disruption and Position Effect}

When the breakpoints in an inversion lie within a gene, the rearrangement can result in a pathologic phenotype. Examples for this rather rare situation are a pericentric inversion inv(16) (p13.3q13), which interrupts the Rubinstein-Taybi locus, and $\operatorname{inv}(\mathrm{X})(\mathrm{p} 11.4 \mathrm{q} 22)$, which affects the Norrie syndrome gene (Gardner and Sutherland 2004). Talaban et al. (2005) investigated two brothers with a maternal inherited inversion of the X chromosome and hypergonadotropic hypogonadism and discussed the altered gene position as a possible cause of the phenotypic abnormalities.

A balanced pericentric inversion can become unbalanced as it is passed on to off-spring of the carrier. This is usually due to difficulties in the alignment and pairing of the recombinant chromosome with the normal homolog during prophase of meiosis I.

\section{Meiosis}

Inversion Loop: Normally, exact pairing of the homologs occurs through the formation of inversion loops in pachytene. Crossing-over in this case follows the reversed loop model, which ensures that the pairing segments of the inverted chromosome and its homolog will be perfectly aligned (homosynapsis) (Gardner and Sutherland 2004).

Aberrant crossing-over between the normal chromosome and the inverted homolog results in the formation of two complementary recombinant chromosomes. These recombinant chromosomes are called reciprocal duplication deficiency chromatids. Progeny with a duplication deficiency are aneusomic, as a conceptus resulting from the fertilisation of such a pathological gamete would have a partial trisomy for one segment and a partial monosomy for the other segment, or the other way around. In most cases, only very small imbalances are viable. Larger imbalances almost invariably lead to a pathological pregnancy course and miscarriage.

The number of crossing-over events in the inversion loop determines whether the meiosis taking place will be normal or abnormal. An uneven number of chiasmata leads to complementary recombinant chromosomes.

Partial Pairing: The inversion loop is not the only configuration which may form during pairing of homologous chromosomes carrying an intra-chromosomal rearrangement. If the inverted segment is sufficiently small, partial pairing occurs if the two distal segments in the long and in the short arm, sometimes even just one of them, can pair. 
Heterosynapsis: A third option for regulation of meiosis in the presence of an inversion is for the two homologs to align without forming a synaptic complex. This is defined as a heterosynapsis (Gabriel-Robez and Rumpler 1994). As a consequence, crossing-over cannot take place within the inverted segment and recombinant chromosomes do not form.

\section{Recombination Frequencies}

Sperm studies of men carrying inversions have been instrumental in estimating recombination frequency during male gametogenesis (Martin 1988a). Studies were carried out separately for long and short inverted segments, and the results showed a remarkably wide range of recombination frequencies for long inverted segments (Bocian et al. 2005). In contrast, no recombination is found in chromosomes with small inverted segments (Balicek 2001).

From the results available to date, Gardner and Sutherland (2004) conclude that recombination events become more probable as the length of the inverted segment increases. In prenatally diagnosed inversions which appear to be balanced, the relevance of the cytogenetic finding should only be discussed further with the consulting family if a similar phenotype accompanied by identical breakpoints is known from published investigations.

\section{Genetic Risks for Carriers of Inversions}

Unbalanced Karyotype in the Offspring: Carriers of a pericentric inversion have an increased risk of having a recombinant child with an unbalanced karyotype. This risk is dependent upon the chromosome and the length of the inverted segment (Saura et al. 1983; Balicek 2001; Bocian et al. 2005). The most frequent complication is the duplication deficiency described above, e.g. a partial duplication accompanied by partial deletion. In addition, duplications and deletions can be an isolated occurrence. Depending on the gene content of the regions involved in these structural aberrations, the resulting phenotype will be characterized by more or less severe abnormalities which can be lethal in some cases.

Some families carrying only small inversions have been described in which the aberrant chromosome was transmitted through several generations. Many carriers were identified in these families who all had the balanced inversion. Both carriers and non-carriers had an identical rate of both miscarriages and death in the neonatal period (Voiculescu et al. 1986; Rivas et al. 1987).

Kaiser in 1988 found that, apart from some few exceptions, the average relative segment length of those inversions leading to recombinant chromosomes was considerably higher $(68.4 \%)$ than the average length of the sum of the inversions (38.4\%). Accordingly, recombinant chromosomes resulting from inversions are usually found in those cases in which the inverted segment measures more than a third of the total length of the chromosome. There is a correlation between the probability of unbalanced offspring and the length of the inverted segment, but it is non-linear. Instead, it appears to be regulated by the probability of a crossing-over event within a specific chromosomal segment as well as by the size of the genetic imbalance of a recombinant chromosome. Various authors surmise equal recombination rates for euchromatin and heterochromatin, meaning there may be an absolute segment size which carries the greatest probability for crossing-over. Smaller segments would not contain recombination points, while larger segments might contain two such points, thus allowing two crossing-over events to take place between the chromatids, possibly even in

Table 1: Frequency of the formation of recombinant chromosomes in 3 cases of pericentric inversions with long inverted segments and case of pericentric inversion with short inverted segment (Martin et al. 1991; Martin 1993; Jenderny et al. 1992; Navarro et al. 1993; Martin et al. 1994)

\begin{tabular}{lcc}
\hline Inversion type & $\begin{array}{c}\text { Relative length of the } \\
\text { inverted region }(\%)\end{array}$ & $\begin{array}{c}\text { Frequency of recombinant } \\
\text { chromosomes }(\%)\end{array}$ \\
\hline Long Inverted Segments & 61 & 31 \\
Inv(3)(p25q21) & 68 & 25 \\
Inv(7)(p13q36) & 68 & 11 \\
Inv(8)(p23q22) & 35 & 0 \\
Short Inverted Segments & & \\
Inv(20)(p13q11.2) & & \\
\hline
\end{tabular}


the absence of pathological recombination. Large segments can support three crossing-over events leading to aneusomic recombinant chromosomes. Thus, the following rule seems to apply: the larger the inverted segment, the higher the probability of crossing-over and formation of a recombinant chromosome. The degree of genetic imbalance is dependent upon the relative size of the inverted segment. The larger the segment is, the smaller the imbalance becomes. This means that duplication deficiencies of relatively large inverted segments may lead to relatively small imbalances which are not lethal. In such a case, the recombinant chromosome is quite similar to the original.

A very long inversion in chromosome 10 described by Roberts et al. (1989) which involved $80 \%$ of the total length, would thus carry an extremely high risk of crossing-over but a comparably low genetic imbalance. In this specific case, a father of three children carried the aforementioned inversion and two of his children had a recombinant chromosome 10 and were phenotypically affected. Intermediate-sized inversions, on the other hand, cause extensive imbalances that are less viable and frequently lead to factors lethal to the gamete or to the embryo.

Furthermore, in these inversions the position of the centromere plays an important role in the genesis of a pathological karyotype. The position of the inverted segment, depending on the structure of the chromosome (metacentric, submetacentric or acrocentric), influences the frequency with which the two aberration types, duplication and deletion, occur. Phenotypically abnormal liveborn offspring more frequently have small partial monosomies caused by deletions and larger partial trisomies caused by duplications.

Quantitative Risks for Unbalanced Offspring: In most cases, the gender of the inversion carrier is of no significance in the context of risks for unbalanced offspring (Kaiser 1984; Stene 1986). However, in some families the female carriers appear to be at higher risk of producing unbalanced offspring than the male carriers are (Sutherland et al. 1976; Pai et al. 1987). Studies performed by Kaiser (1988) confirm these results: paternal inversions were found to be causative in 36 cases of unbalanced offspring as compared to maternal inversions in 46 cases. A de novo mutation was identified in only one case.
Daniel et al. (1989) conducted studies focussing on unbalanced karyotypes on findings from American, Canadian, and some European amniocentesis data. For families who already have an abnormal child and for inversions of short, distal segments, they determined a risk of $10-15 \%$. A French collaborative study conducted in 1986 (Groupe de Cytogénéticiens Français, 1986a), in which data from a total of 305 independent cases of inversion were examined, established that for inversions that do not induce lethal recombinations, there is a risk of no more than $7 \%$ for genetically unbalanced offspring. The authors state that, in their opinion, most such families carry an even smaller risk of at most $5 \%$. These results concur with those obtained by Boué and Gallano, who found a risk of $1.3 \%$ (1984). In their assessment, the actual risk may be even lower, probably as small as $1 \%$. However, each family's risk for unbalanced offspring must be individually assessed and is dependent upon the position of the breakpoints and the structure of the rearranged chromosome in each particular case. Breakpoints located in extremely distal positions cause a higher risk of aneusomie de recombinaison (Dutrillaux et al. 1973, 1980; Winsor et al. 1978; Daniel 1981; Kaiser 1984; Garcia-Heras and Martin 2002). Furthermore, the probability of unequal crossing-over in the inverted segment during pachytene of meiosis I is elevated. Certain inversions may have an extremely high risk, such as inv(4) (30\% risk) and inv(21) (10\% risk) (Fraisse et al. 1986; Léonard et al. 1986).

Carriers of inversions who were ascertained via recombinant offspring have a $5 \%$ risk (males) or a $10 \%$ risk (female) respectively, of having further unbalanced offspring. On the other hand, carriers who were ascertained in the context of screening tests and who have no unbalanced offspring do not appear to have an elevated genetic risk.

Close analysis of inversion families, comprehensive scrutiny of the existing literature, and calculation of the differing degrees of possible imbalances that may occur in carriers of recombinant chromosomes all confirm that each inversion bears its own specific risk (Gardner and Sutherland 2004). For example, for inv(8)(p23q22) the risk for live-born offspring carrying a recombinant chromosome resulting from the inversion is $6 \%$ both for paternal and maternal transmission (Smith et al. 1987). Inversions of 
chromosome 18 with breakpoints in p11, q11, q12 or q21 exhibit a so-called "group risk" of $8 \%$ (Ayukawa et al. 1994).

Because of the difficulties in ascertaining the actual number of miscarriages caused by an unbalanced inversion, there can be no certain estimation of the risk for miscarriage in balanced carriers. In addition, there are such enormous differences depending on the affected chromosome that only generalized risk assessments can usually be attempted, with detailed risks being predicted only in relation to the specific chromosome and breakpoint in each family. In the French collaborative study, 80 families $(26 \%)$ were detected due to increased miscarriage rates. The value generally quoted in the literature is $7 \%$, which may perhaps be underestimated, just as $26 \%$ is probably too high a rate. It is certainly safe to say that inversions increase the risk for miscarriages, with particular emphasis being placed on chromosomes $2(35 \%), 5(32 \%)$ and 11 (33\%).

Significance of Gene Content in Recombinant Gametes: The viability of a recombinant conceptus does not depend solely on the size of the unbalanced segment, but also on the genetic content. The involvement of a small segment means that the combination of duplication and deletion resulting from the recombinant chromosome may permit a normal or relatively normal pregnancy and that the child will then have a chromosome syndrome. On the other hand, the recombinant chromosomes in inversion carriers in whom one or both distal segments are large exhibit such a grave degree of imbalance that there is practically no chance of survival to livebirth. Thus, persons with a potentially large chromosomal imbalance will practically never bear children with an unbalanced karyotype or a chromosome syndrome (Gardner and Sutherland 2004).

In many cases only one of the recombinant chromosome forms is viable. Only very rarely are both recombinant chromosomes that may result from the same inversion, namely the dup/del and the del/dup, viable. The birth of phenotypically abnormal children who can be shown to have a recombinant chromosome deriving from a parental inversion is the only certain proof that an unbalanced chromosome aberration is nonlethal. The formation of unbalanced recombinations appears to be impacted by the chromosome type.
Infertility: In the French collaborative study (1986a), 12\% of inversions (36 cases) were found due to male infertility and 3\% (10 cases) were found due to female infertility. Dutrillaux et al. examined 958 infertile men and showed that pericentric inversions occurred twice as often in these subjects as in the general population (1982). These results are in accordance with other studies which demonstrated that the relative reproductive fitness of male inversion carriers is noticeably reduced (Jacobs et al. 1975; Morton et al. 1975). A comparison of the transmission rates for maternal versus paternal inversions in the French collaborative study shows that the maternal rate is almost twice as high (78 versus 42). In 18 informative families (not including inversions in the heterochromatin of chromosomes 9, 16 and $\mathrm{Y}$ ) inversions were transmitted more frequently by the mother in 14 cases, as compared to the father in 3 cases; in one family the rates were comparable. These results may not constitute direct proof. However, they do indicate quite clearly that there is a distinct reduction in male fertility and consequently, a decreased transmission of the inversion chromosome. In addition, chromosome specific differences must be taken into account: the reduced number of children is considerably more marked for male carriers of inversions affecting large chromosomes than it is for the smaller chromosomes. Apparently, inversions of chromosome 1 are particularly significant in the etiology of male infertility. Thus, in the French collaborative study, 7 out of 12 cases (58\%) were ascribed to an aberrant chromosome1. Only one man with an inv(1) was able to father children. Meschede et al. (1994) also describe an inversion in chromosome 1 in two brothers with azoospermia. In one brother, spermatogenesis was histologically shown to be impaired at the level of the primary spermatocyte. Both men carried an inv(1)(p34q23) of maternal provenance. In 271 subfertile males, Dutrillaux et al. (1982) identified 57 chromosome aberrations (21\%), of which five were inversions ( $1.8 \%$ or $18 \%$ of all probands). This number is considerably higher than the 0.5 $\%$ o frequency of inversions found in the general population. Gabriel-Roberts and Rumpler (1994) surmise that the probability of a homolog synapsis being disturbed increases with the size of the chromosome. The aberrant pairing would in turn disturb certain cellular mechanisms vital to spermatogenesis, resulting in a halted develop- 
ment and ensuing infertility. The correlation between pericentric inversions and infertility is interpreted in different ways by the various authors studying the subject. Giraldo et al. (1981) assume that there may be a dependence on the gender of the transmitting parent, such as the one found for translocations, where fertile women transmit the aberrant chromosome to infertile sons. However, this hypothesis did not turn out to be generally applicable. Teyssier and Moreau (1983) identified an inv(10)(p11q21) that was transmitted from father to son. Dutrillaux et al. (1982) consider autosomal rearrangements, including inversions, to be not the cause but rather an additional negative factor in men whose sperm quality is subnormal, anyway. Teyssier and Moreau (1983), on the other hand, do not think it probable that a change in the expression of the genes at or very near the chromosomal break points could cause spermatogenesis to be halted in men with chromosomal rearrangements. Rather, they assume a disturbance of mechanisms controlling the development of sperm. Furthermore, they conjecture that in man, just as in the mouse, the presence of chromosomal rearrangements such as translocations and inversions causes an incomplete synapsis as of pachytene, which in turn permits an association of these autosomal, non-pairing regions with the bivalent sex chromosomes. This non-homologous pairing between the autosome and the XY bivalent could then interfere with the inactivation of the XYcomplex, which is a basic requirement for the maturation of male gametes. This hypothesis can be confirmed through electron microscopic analysis of the synaptonemal complex during pachytene, as well as via fluorescence in situ hybridisation (FISH) of the aberrant chromosome with the XY bivalent (Anne Chandley, pers. communication). Furthermore, it has been demonstrated that among subfertile males with autosomal rearrangements, those men possess the highest fertility who exhibit the lowest frequency of association between the rearranged chromosome and the XY bivalent. This would also explain the exclusively male nature of this type of infertility, as the two $\mathrm{X}$ chromosomes stay active during the meiosis of the female gametes and pair throughout their entire length, just like the autosomes.

It may be assumed that infertility occurs only in heterozygous carriers of chromosomal rearrangements, while homozygous carriers of any rearrangement show normal fertility. This might be explained by the fact that a new bivalent is formed in the homozygous state. This would eliminate the difficulties that can otherwise accompany the pairing of the bivalent, and thus, no unpaired segments interfere with the inactivation of the XY bivalent.

Inversions do not seem to influence female fertility to any noticeable degree apart from an increased miscarriage rate, however, unbalanced karyotypes may occur. For example, Teyssier and Moreau (1983) reported two cases in which women transmitted an inv(10). These women each had one child that exhibited numerous phenotypical abnormalities. A so-called aneusomie de recombinaison due to the inversion caused the formation of unbalanced gametes. However, the birth of such children with a chromosome syndrome is a rare event.

Inversions in Religious and Geographic Isolates: A number of studies indicate that there are differences in the frequency with which inversions occur in various populations. Investigations within the context of the French collaborative study (1986a) found that, of 305 persons included in the study, 150 had an inv(2)(p12q14). There was no de novo case among them. Most of these families were of Jewish descent and originated from North Africa, especially Algeria and Morocco, or Spain and Portugal. A number of these families were of French descent. In some cases, those inversion carriers who originated from North Africa traced their family back to ancestors living in Spain before the Inquisition. At present it is not possible to trace all these cases to a single mutation. It is, however, probable that there were a few mutations originally, of which one occurred prior to the mass emigration of the Jewish community from Spain in the $15^{\text {th }}$ century.

Inter-and Intrachromosomal Unequal Segregation of the Balanced Inversion: Published data pertaining to the transmission of inversions are controversial. Boué and Gallano (1984) found a preferred transmission of the inversion chromosome in the descendants of male inversion carriers. Iselius et al. obtained further results through investigation of 216 families (1985). Though they did not find a significant deviation from the expected $1: 1$ segregation ratio in the descendants of male and female carriers, they did detect altered patterns of transmission for certain chromosomes, after 
factoring out the proband himself, as well as his direct descendants and their families. They observed an increased transmission of the aberrant chromosomes 5, 7, 11 and 21 on the one hand, and a decrease in the transmission of aberrant chromosome $1,6,12$ and 20 on the other hand. This was taken as proof that certain inversions are passed on either more or less frequently to the following generations than others.

In addition, researchers found preferential patterns of transmission for defined chromosome regions inv(2)(p12q14), inv(5)(p14q14), inv(10) (p11.22q21.109), inv(10)(p1209q11.109) and $\operatorname{inv}(21)(\mathrm{p} 12 \mathrm{q} 2109)$.

Risk for Aneuploidy: The afore-mentioned French researchers happened upon a large proportion of the inversion families only through effects caused by other structural or numerical chromosomal aberrations. Analysis of these families showed that the risk for autosomal trisomies is comparable to the one in families with a normal karyotype.

The authors came to the conclusion that generally speaking, inversions do not of themselves predispose to any other specific and independent chromosome anomaly. However, in the case of inv(18) and inv(21), there does seem to be a direct correlation between the inversion in a parent and the occurrence of the respective trisomy in his or her offspring, as indicated by the births of a number of trisomic children in the families of several carriers of these inversions. Thus, it is to be assumed that the risk for these trisomies is increased for the progeny of inversion carriers for chromosomes 18 and 21 . The reason appears to be abnormalities in the formation of the bivalent during meiosis I.

However, this restriction of an aneuploidy risk for inversion carriers was not in accordance with the findings of other investigation groups. Investigations of an inv(9) performed by Kaiser (1988) focussed on four patients with a trisomy 9 mosaic and one patient with a partial trisomy 9. Furthermore, he discusses three published cases of an inv(22) in which the carriers have a conceptus with trisomy 22 , and three family members possess an additional ring chromosome 22. As both trisomies 9 and 22 are extremely rare, a coincidental correlation does not seem very probable.

In 1983, Saura et al. described the case of the very rare inv(22) which was detected only through a phenotypically conspicuous child. The child had a trisomy 21 , a Klinefelter syndrome, and a pericentric inversion of chromosome 22. The phenotype was as follows: $48, \mathrm{XXY},+21$, inv(22)(p11q12). The inversion was of maternal origin. They also mentioned an inv(22) that was ascertained through a partial trisomy 22 . The authors discussed the term "interchromosomal effect", which was introduced by Sturtevant in the course of his studies of Drosophila (1926) and which was first applied to the field of human genetics by Lejeune in 1963. Saura et al. assumed that, just like other balanced structural rearrangements, pericentric inversions are capable of influencing the segregation of other chromosomes. Their analysis of the parental karyotype for a large number of children who had a trisomy 21 showed an elevated frequency of balanced translocations that was noticeably higher than the expected rate of 1-2\% (de Grouchy and Turleau 1982). The authors go on to point out that, of the six published pericentric inversions which are thought to influence the malsegregation of other chromosomes, four cases involved acrocentric chromosomes, and that their own observations constitute a further example of this type of chromosome.

The frequency of aneuploidies is according to the investigation of Nielson et al. increased in the progeny of inversion carriers. The $0.42 \%$ frequency found in new-borns (Nielsen et al. 1982) in conjunction with the values given in the French collaborative study, point to an increase of the aneuploidy risk by a factor of about 3.2.

In the case of a pericentric inversion on chromosome 10 which was present in two generations of a family investigated in our own laboratory and which caused no phenotypical effects, a pedigree analysis succeeded in disproving any direct association between the inversion and both a miscarriage as well as a triploidy syndrome $(69, \mathrm{XYY})$ in the third generation. A phenotypically normal woman carried an inv(10). During a pregnancy which followed upon a miscarriage, she opted for prenatal diagnosis, which revealed a triploidy syndrome. The fact that the additional genome was of paternal origin (as indicated by the additional $\mathrm{Y}$ chromosome) proved that, in this family, there was no connection between the inversion and the polyploidy.

Pathological Phenotype in Apparently Balanced Inversions: In the French collaborative 
study, $24 \%$ (or 72 out of 304 ) of the inversion carriers were detected due to a proband with an apparently balanced karyotype who was nevertheless phenotypically conspicuous. A summary of the literature published by Kaiser (1984) quotes an even higher rate $(31 \%)$. Furthermore, Kaiser states that a larger proportion of fathers with inversions were identified due to a phenotypically abnormal child. This observation was checked in the context of the French collaborative study using a collective of 120 probands whose inversions were of paternal origin. The disequilibrium described by Kaiser was not verified for the French collaborative study.

Kaiser also observed a greater number of de novo versus familial inversions in phenotypically abnormal probands. The same trend was visible in the French collaborative study, albeit not in any statistically relevant measure. It is to be assumed that the pathological phenotype in these cases is caused by sub-microscopic aberrations such as microduplications or microdeletions, or possibly by uniparental disomy (UPD)(see below). Kaiser goes on to name several other possible explanations, e.g. localisation of the inversion breakpoint within a cistron, preventing the expression of the genetic information therein, and further, the shifting of genetically active DNA into the neighbourhood of heterochromatin, which could result in a heterochomatinization and thus an inactivation of previously euchromatic segments (1988).

Uniparental Disomy: Carriers of a balanced pericentric or paracentric inversion have an increased risk for abnormalities in the formation of bivalents during prophase of meiosis I, such that univalents occur. As a consequence, gametes with a disomy or a nullisomy for the respective chromosome arise, and the zygote develops a trisomy or a monosomy. The processes of monosomy or trisomy rescue may then follow postzygotically, and the embryo would exhibit an UPD.

\section{Inversions of the Sex Chromosomes}

$X$ Chromosome: Pericentric inversions of the X chromosome are rare (Duckett and Young 1988; Therman et al. 1990; Schorderet et al. 1991). They have been implicated in gonadal dysfunction in women. Some of the affected women were of normal intelligence, while others were mentally retarded. However, a number of female inversion carriers have been found to possess normal gonadal function.

In 1982, Keitges et al. described dizygotic female twins who both had the same pericentric inversion in $\mathrm{X}$ but exhibited completely different symptoms: one twin was phenotypically inconspicuous with normal intelligence and menstrual cycles, while the other twin showed a slight degree of mental retardation, psychological problems, irregular menstruation, and slightly dysmorphic features. A selective inactivation of the inverted $\mathrm{X}$ chromosome was demonstrated in the latter twin. The authors proposed the following possibilities: 1 ) the noninverted X chromosomes differed in the two girls, 2) the abnormal twin possessed a deletion or a duplication that was below the detection level, or 3 ) these observations were a coincidence.

Pericentric $\mathrm{X}$ inversions may be transmitted by healthy carriers of both genders. The transmission of $\mathrm{X}$-chromosomal inversions through several generations in different families, with no evidence of recombinations and thus no phenotypical consequences, has been analysed.

In contrast to autosomal balanced inversions, the inversions that occur on the sex chromosomes more frequently cause disturbances of gene function. Thus, certain breakpoints can distinctly influence the phenotype.

Phenotypical changes caused by inversions differ depending on the affected gender. Women are usually phenotypically inconspicuous. However, a position effect can become evident if the breakpoint lies within the region Xq13-q26, leading to gonadal dysfunction (Therman et al. 1990).

Gardner and Sutherland (2004) state that an ovum with a normal $\mathrm{X}$ or an intact inverted $\mathrm{X}$ chromosome will produce a normal child. In families where the balanced inversion of the $\mathrm{X}$ chromosome is compatible with normal germline development in the female carriers, girls inheriting the inversion from their mothers should also develop normally.

The consequences of the unbalanced inheritance of a maternal $\mathrm{X}$ inversion are much more critical in the male child (French Collaborative Study 1986b).

In contrast, in males (who are hemizygous carriers of a balanced inv(X)) there are no consequences for the phenotype or fertility. The normal course of meiosis is not disrupted, and recombination cannot take place within the 
inverted segment. All daughters of such a male carrier will, of course, inherit the inversion from their father in a balanced form. Most of these women exhibit normal gonadal development, albeit some few cases of premature menopause have been reported. As the sons inherit their X chromosome from their normal mothers and the $\mathrm{Y}$ chromosome from the inversion-carrying fathers, they possess normal karyotypes.

Some carriers have been found to have mosaics with a $45, X$ cell line.

$Y$ Chromosome: Inverted Y chromosomes usually have a metacentric structure and are unchanged in size. The breakpoints are most frequently located in the euchromatin of the long and the short arm, near the centromere: $\operatorname{inv}(\mathrm{Y})(\mathrm{p} 11 \mathrm{q} 11)$. The frequency of pericentric inversions ranges from $0.07 \%$ to $5.7 \%$ according to the ethnic group investigated (Wyandt and Tonk 2004).

In most cases, the inversion of the $\mathrm{Y}$ chromosome does not adversely influence fertility. In some rare cases, the breakpoints of a pericentric $\operatorname{inv}(\mathrm{Y})$ are located in the euchromatin within critical regions such as the DAZ gene, and then phenotypical consequences such as infertility or subnormal fertility can result. Meiosis of the inverted Y chromosome proceeds normally, and pairing difficulties between the $\mathrm{X}$ and the $\mathrm{Y}$ chromosome can be eliminated as a reason for azoospermia and oligospermia. Furthermore, the fact that meiotic pairing of the inverted $\mathrm{Y}$ with the $\mathrm{X}$ chromosome is not inhibited shows that the distal regions of the short arm are not affected.

\section{Paracentric Inversions}

\section{Inversions of the Autosomes}

Formation and Frequency: According to newer research, paracentric inversions constitute one of the more frequent forms of chromosomal rearrangements. In this type of inversion, both breakpoints are located on one arm of the same chromosome. Thus, the centromere is not involved in the rearrangement. The mutation is apparent in the altered banding pattern, provided the inverted segment comprises more than one band. Offspring of carriers of paracentric inversions have only a slightly elevated risk for an unbalanced karyotype.

For a long time, paracentric inversions were less well characterized than were pericentric inversions, primarily because their size often precluded detection. Up until the development of modern banding techniques in 1970, it was not possible to detect them at all in mitotic chromosomes.

Published studies describe a total of 75 independent cases documented up until 1986. The central study performed by the French group of cytogeneticists (1986b) increased that number to 107. In 1995 Pettenati et al. published a review of 446 probands with paracentric inversions, including 120 new cases. This means that in comparison to the data obtained for pericentric inversions, paracentric inversions would occur approximately ten times less frequently, a number which, for reasons described above, does not seem credible.

Molecular cytogenetic investigations showed that there are a significant number of paracentric inversions among submicroscopic structural aberrations. These have been found mainly in the subtelomeric regions of the chromosomes, but proximal regions are also involved. Among these is the best characterized cryptic paracentric inversion, involving the Williams Beuren region in the long arm of chromosome 7 (7q11.23). Investigations have shown that approximately $30 \%$ of parents of children with Williams Beuren Syndrome have a paracentric inversion in the critical region on chromosome 7 (Osborne et al. 2001; Valero et al. 2000; Scherer et al. 2005).

One problem in analysing paracentric inversions and defining their genetic risk is the possibility that heterologous insertions may be mistaken for inversions. Often, the application of FISH probes is the only method to differentiate between the two options. This is of special relevance when genetic risks are given to families seeking genetic counselling, as the risks are significantly higher for carriers of insertions (about factor five) than for carriers of paracentric inversions (Madan and Nieuwint 2002; Balicek 2004).

Meiosis: In general, it can be said that both paracentric and pericentric inversions do not of themselves give rise to phenotypical abnormalities. However, a meiotic crossing-over event within the inverted segment in balanced carriers can result in the formation of chromosomally imbalanced gametes. The risk for this type of imbalance depends upon the pairing possibilities and the probability of crossing-over in the inverted segment, which is in turn proportional to the length of the inversion. 
Special genetic risks for unbalanced recombinants apply for chromosomes 9, 14, and 18. In chromosomes 9 and 14, stable pseudo-dicentric derivatives can develop, and in chro-mosome 18 , different types of small duplications and/or deletions lead to handicapped carriers with almost normal life expectancy (Madan and Nieuwint 2002).

Inversion Loop: Pairing within the inverted segment is accomplished through formation of an inversion loop during pachytene. Generation of chiasmata then leads to formation of dicentrics and acentric fragments. If there is no pairing between the homologs, and consequently no crossing-over takes place, then meiosis proceeds normally.

Since meiotic behaviour of chromosomes with paracentric inversions in females cannot be studied in large numbers of human oocytes, investigations in mice are performed for comparison. Exchange and segregation patterns were compared for inversion carriers and for normal controls. While the exchange rate was greatly increased in inversion carriers, nondisjunction rate was only slightly higher (Koehler et al. 2004). Further investigation will allow comparison of these results on female meiosis in mice with paracentric inversions with findings in human inversion carriers.

Investigations of male meiosis in inversion carriers are preferentially performed via analysis of sperm. The recombination rates observed were low, and increased nondisjunction was not documented (Martin 1986; Devine et al. 2000; Anton et al. 2005).

Partial Pairing and Heterosynapsis: These peculiarities of meiosis have not been observed for paracentric inversions.

Genetic Risks for Inversion Carriers: Classic genetic theory states that heterozygote carriers of an autosomal paracentric inversion are not capable of producing unbalanced, abnormal offspring. This is true for the majority of paracen-tric inversions, but some exceptions have been observed.

The French group of cytogeneticists (1986b) found that reproductive fitness of heterozygous inversion carriers was normal in 32 families they examined. Fertility of the inversion carriers can be classified based on the number of offspring produced, and the couples in the French collaborative study had an average of two children each. Reduced fertility such as was observed for the male carriers of pericentric inversions was not an issue for paracentric inversion carriers.
In the afore-mentioned French study, 11 carriers of paracentric inversions were detected due to miscarriages, eight were found in the context of systematic studies, and five were detected because of malformations despite an apparently balanced karyotype. The distribution which can be drawn from literature is based on different numbers: 11 cases, or $15 \%$, through miscarriages, 20 cases, or $27 \%$, due to malformations/ balanced karyotype, and $10(13 \%)$ in combination with other chromosomal imbalances. These data suggest that the risk for malformations is particularly high among the carriers of paracentric inversions. However, this impression is false. It must be taken into account that published studies tend to concentrate on interesting cases, leading to an unrealistically high number of aberrations described in the context of paracentric inversions. Of the 32 probands in the French study, four were detected due to familial translocations (two each Robertsonian and reciprocal). This percentage illustrates the usually coincidental nature of the discovery of such inversions. In one case there was a complex chromosome rearrangement (CCR) with three breakpoints, i.e. the inverted segment was inserted in an entirely different area of the chromosome. According to this study, only four published cases appeared to be aneusomic, and only in one case was the nature of the rearrangement clearly defined: Mules and Stamberg (1984) described a stable, dicentric inversion duplication which had apparently resulted from a maternal inv(14). Madan (1988) characterized six cases with additional aneuploidies in a collective of 65 carriers of paracentric inversions: four patients with Klinefelter Syndrome, one with Down Syndrome, and one with Turner Syndrome. However, the author states that these rates are normal for any collective. Thus, he discounts the possibility that a paracentric inversion could increase the probability of nondisjunction. The risk for aneusomy is estimated to be low, approximately $1 \%$ among the offspring of carriers of paracentric inversions due to the fact that stable, pseudodicentric chromosomes may be produced.

The birth of chromosomally abnormal children is often thought to be related to the existence of a paracentric inversion. Usually the real cause is more likely to be an intrachromosomal insertion, which bears a $15 \%$ risk for the production of unbalanced offspring.

Segregation of Balanced Inversions: Out of 
40 chromosomally characterized offspring of inversion carriers, the authors of the French study found 29 who had inherited the inversion. At first glance this seems to point to a preferential segregation of the inverted chromosome, but in reality it is more probably the result of an insufficient number of cases. The exclusion of factors which may unduly influence the results leaves a proportion of 13 inversion carriers to 8 noncarriers, which is a ratio of approximately $2: 1$. Published studies which in-corporate sufficiently large numbers of family members are quite rare, basically coming down to only two groups' results (Romain et al. 1983; Venter et al. 1984). Here, a transmission of the inversion was found in 11 out of 22 cases, which corresponds to a ratio of $1: 1$. Due to the small number of cases, the significance of these numbers must be considered uncertain, too.

The gender distribution of paracentric inversions was examined in 22 families as well as in several isolated cases (70 inversion carriers in total). There were 35 male and 35 female carriers. Of the 32 index patients (probands), 18 were male, and 14 were female. 14 parents of probands were inversion carriers ( 7 mothers, 7 fathers), all of which corresponds to a ratio of 1:1. Here, too, the relatively low number of cases limits the informative value.

Other published studies give a higher number of male (38) than female (28) carriers of paracentric inversions, and they also find more frequent maternal (30) than paternal (19) transmission. However, the deviation from the 1:1 ratio described by the French group is not significant (1986b).

Uniparental Disomy: Just like pericentric inversions, paracentric inversions can give rise to secondary rearrangements with deletions in the inverted segment.

Repeated cases of familial Angelman and Prader-Willi Syndromes confirm the relative frequency of such events, which may possibly occur more often with paracentric than with pericentric inversions. Furthermore, in addition to intrachromosomal or homolog rearrange-ments, there is also the possibility of nondis-junction and UPD due to abnormalities of synapses during meiosis (Engel and Antonarakis 2002).

\section{Inversions of the Sex Chromosomes}

X Chromosome: Paracentric inversions of the $\mathrm{X}$ chromosome are relatively rare, so there are no reliable data on their frequency. There is a wide range of phenotypes.

Just as in pericentric inversions of the $\mathrm{X}$ chromosome, break points in the critical region Xq13-26 of the long arm generally result in gonadal dysfunction. Breakpoints located outside of the critical region usually permit a normal phenotype and normal fertility.

The mental capacities of women with paracentric inversions of the $\mathrm{X}$ chromosome vary. Some exhibit normal intelligence, whereas some are mentally retarded. Although there is usually no great variance within families in this respect, there can be both mentally retarded and intellectually normal inversion carriers in the same family (Neu et al. 1988).

Equally, male carriers of a paracentric inversion of the $\mathrm{X}$ chromosome may present with fertility problems or mental retardation.

$Y$ Chromosome: to our knowledge there are no published cases of paracentric inversions of the Y chromosome. However, submicroscopic inversions cannot be excluded.

\section{REARRANGEMENTS OF THE CONSTITUTIVE HETEROCHROMATIN}

\section{Characterization of the Heterochromatin}

The human genome comprises two main groups of heterochromatin, namely facultative and constitutive heterochromatin. Euchromatic segments or the whole $\mathrm{X}$ chromosome which were inactivated during early stages of embryonic development and can remain condensed throughout many cell generations are designated facultative heterochromatin.

Constitutive heterochromatin, on the other hand, is composed of distinctly structured chromatin which is non-coding and repetitive. Two groups of repetitive DNA can be distinguished: highly repetitive and medium repetitive DNA. The first group is made up mainly of classic satellite DNA I-IV. The other frequent forms are $\alpha$ and $\beta$ satellite DNA. The majority of the satellite DNA I-IV is situated in heterochromatin blocks in 1q12, 3q11.2, 4q11.2, 9q12, 15p11.2, $16 q 11.2$ and Yq12. Medium repetitive heterchromatin is interspersed throughout the euchromatin. The repeat regions may be preferred breakpoints and lead to rearrangements such as inversions.

Homologous chromosomes are generally 
heterozygous for length polymorphisms of the constitutive heterochromatin. These variations are termed heteromorphisms. Heterochromatic areas also differ in regard to the amount of satellite DNA they contain.

A number of studies could not prove that carriers of large heteromorphisms show reduced fertility or may produce offspring with chromosomal imbalances (Wyandt and Tonk 2004). Inversions lead to positional changes of the polymorphic regions and thus might influence gene expression. Partial amplifications or deletions of the constitutive heterochromatin might result in a loss or an increase of gene function.

\section{Pericentric Inversions}

\section{Inversions of the Autosomes}

Characterization and Frequency: Pericentric inversions occur in the vicinity of the centromere in heterochromatin blocks on chromosomes 1,3 , 4, 9 and 16, not, however, in 15p11.2. The heterochromatin block on the Y chromosome is located in the distal segment and can be inverted as well. Evidence to date shows that inversions of the heterochromatin on chromosomes 1, 3, 4, 9, 16 and $\mathrm{Y}$ are genetically irrelevant and that these inversions may be considered variants or polymorphisms (Kalz and Schwanitz 2004; Wyandt and Tonk 2004).

Kalz studied the frequency of inversions in the heterochromatic regions of the aforementioned chromosomes (2003). A collective consisting of 817 persons was examined in regard to inversions in the autosomes. Heterochromatin blocks were stained via various banding techniques. 1q12, 9q12, 15p11.2, and 1611.2 were stained via CBG-banding and DA/DAPI, while heterochromatin in 3 q11.2 and 4 q11.2 was detected through QFQ-banding alone (exclusively fluorescence polymorphisms) and Yq12 was stained using all three techniques. Only one inversion was found in $1 \mathrm{q} 12(0.12 \%$ of probands); 20 inversions in $3 q 11.2(2.45 \%) ; 124$ in $4 q 11.2(15.18 \%)$; 16 in $9 q 12(1.96 \%)$ and none in $16 q 11.2(0 \%)$. Inversions of the constitutive heterochromatin in the $\mathrm{Y}$ chromosome were studied in 409 men. Only one inversion was found, which corresponds to a frequency of $0.25 \%$. Kaiser gives slightly different values obtained in his study of 352 cases with complete and partial inversions (1988) (see Table 2).

Both studies specify very similar figures for the $\mathrm{Y}$ chromosome, but the results diverge for chromosomes 1 and 9. The reason for this discrepancy is the use of differing criteria for inclusion in the data. While Kalz and Schwanitz included only complete inversions, Kaiser also registered partial inversions for chromosomes 1 and 9.

According to Gosden et al. (1981) and Mattei et al. (1981), the heterochromatin segment on chromosome 9 consists of two biochemically distinct subunits leading preferentially to partial inversions.

\section{Inversions of the Sex Chromosomes}

Pericentric Inversions of the Y Chromosome: Inversions of the Y chromosome inv(Y) (p11q12) are quite common in the general population (Verma et al. 1982; Tóth et al. 1984). This specific inversion occurs in 0.6 per thousand male persons, which corresponds to a frequency of $0.06 \%$. Gersen and Keagle (1999) describe a certain ethnological group in South Africa, namely the Gujerati Muslims, in which the inversion occurs with a frequency of $30.5 \%$, which may be assumed to be the result of a founder effect.

The inversion break points in Yq almost

Table 2: Frequency of complete pericentric inversions of the heterochromatin in chromosomes 1, 3, 4, 9, 16 and Y (Kalz and Schwanitz, 2004) as compared to data for complete and partial inversions obtained by Kaiser (1988). n/a: not analysed.

\begin{tabular}{lcccc}
\hline & Kalz & & & $\begin{array}{c}\text { Kaiser (complete } \\
\text { and } \begin{array}{c}\text { partial } \\
\text { inversions) }\end{array}\end{array}$ \\
\cline { 2 - 5 } Chromosome & Number of probands & Number of inversions & Frequency (\%) & Frequency (\%) \\
\hline $1 \mathrm{q} 12$ & 817 & 1 & 0.12 & 0.3 \\
$3 \mathrm{q} 11.2$ & 817 & 20 & 2.45 & $\mathrm{n} / \mathrm{a}$ \\
4q11.2 & 817 & 124 & 15.18 & $\mathrm{n} / \mathrm{a}$ \\
9q12 & 817 & 16 & 1.96 & 11.35 \\
$16 \mathrm{q} 11.2$ & 817 & 0 & 0 & $\mathrm{n} / \mathrm{a}$ \\
Yq12 & 409 & 1 & 0.25 & 0.15 \\
\hline
\end{tabular}


invariably lie in the heterochromatic region or pericentromeric. Therefore, this $\operatorname{inv}(\mathrm{Y})$ is not associated with phenotypical abnormalities. Neither is there an increased risk for the birth of an abnormal child. For these reasons, and because of its relative frequency, this $\operatorname{inv}(\mathrm{Y})$ is considered genetically irrelevant.

The pairing of the XY bivalent usually takes place via the tips of the short arms. Usually, a pericentric inversion does not adversely affect this process, and the inversion is transmitted unaltered to the next generation. However, sometimes a secondary rearrangement $t(X ; Y)$ does occur, and in this case it is to be assumed that there was a primary inversion followed by a sporadic translocation during paternal meiosis. This assumption is supported by the observation that in no sporadic case of $\mathrm{t}(\mathrm{X} ; \mathrm{Y})$ was an inversion ever found in the (paternal) Y chromosome.

\section{FREQUENCY OF INVERSIONS AMONG THE STRUCTURAL ABERRATIONS}

Chromosomes 2, 5, 7 and 10 were examined more closely in an attempt to delineate the frequency of euchromatic inversions as one of the many types of structural aberrations (translocation, duplication, deletion, insertion and ring chromosome). Data was compiled on the basis of the summary provided by Borgaonkar in Chromosomal Variation in Man (1997). A total of 3212 cases were analysed (see Table 3). Inversions were most frequently found for chromosome 2 (10.91\%), and they were least frequent for chromosome $7(6.47 \%)$, with a comparable total of aberrations being found for chromosomes 2, 5 and 7. These data confirm that there is a differing interchromosomal frequency of inversions. Chromosome 2, which exhibits the highest frequency of inversions, is also the largest chromosome. In addition to size, however, there must be other factors determining the inversion rate, as is illustrated by the similar size of chromosomes 7 (5.36\% of the total length of the genome) and $10(4.58 \%$ of the total length of the genome) and their different inversion frequencies (Table 3).

Analysis of the euchromatic inversions of chromosomes 2, 5, 7 and 10 was carried out for five different categories: familial, unidentified, $d e$ novo, homozygous and mosaic cases. For all four chromosomes the number of inversions of unidentified genesis was highest, followed by familial inversions (Table 4). However, it may be assumed that some of the inversions of unidentified genesis are actually familial inversions that were not recognized as such because the parents or the grandparents were not examined and thus not distinguished as the carriers of this rearrangement.

De novo inversions were very much less frequent than the familial ones (Fig. 1), but they were found for every one of the four analysed chromosomes. A homozygous inversion was found only in one case, for chromosome 2 . Furthermore, only 2 mosaics were detected, and these concerned chromosome 2.

Within our own investigation group (91

Table 3: Total number of structural aberrations for chromosomes 2, 5, 7 and 10, including inversions (absolute and in percentages) according to Borgaonkar (1997).

\begin{tabular}{lccc}
\hline Chromosome & $\begin{array}{c}\text { Number of structural } \\
\text { aberrations }(n)\end{array}$ & $\begin{array}{c}\text { Number of } \\
\text { inversions }(n)\end{array}$ & $\begin{array}{c}\text { Inversion } \\
\text { incidence (\%) }\end{array}$ \\
\hline 2 & 862 & 94 & 10.91 \\
5 & 888 & 77 & 8.67 \\
7 & 819 & 53 & 6.47 \\
10 & 643 & 49 & 7.62 \\
\hline Total & 3212 & 273 & \\
\hline
\end{tabular}

Table 4: Differentiation of the inversions for chromosomes 2, 5, 7 and 10 according to their origin and the number of mosaic and homozygous cases $(n=273)$.

\begin{tabular}{|c|c|c|c|c|c|c|}
\hline \multirow[t]{2}{*}{ Chromosome } & \multicolumn{3}{|c|}{ Origin of Inversion } & \multicolumn{2}{|c|}{ Special Forms } & \multirow[t]{2}{*}{$\overline{\text { Total }}$} \\
\hline & Familial & Unidentified & De novo & Homozygous & $\overline{\text { Mosaic }}$ & \\
\hline 2 & 26 & 55 & 5 & 1 & 2 & 94 \\
\hline 5 & 32 & 42 & 3 & - & - & 77 \\
\hline 7 & 23 & 26 & 4 & - & - & 53 \\
\hline 10 & 23 & 25 & 1 & - & - & 49 \\
\hline
\end{tabular}




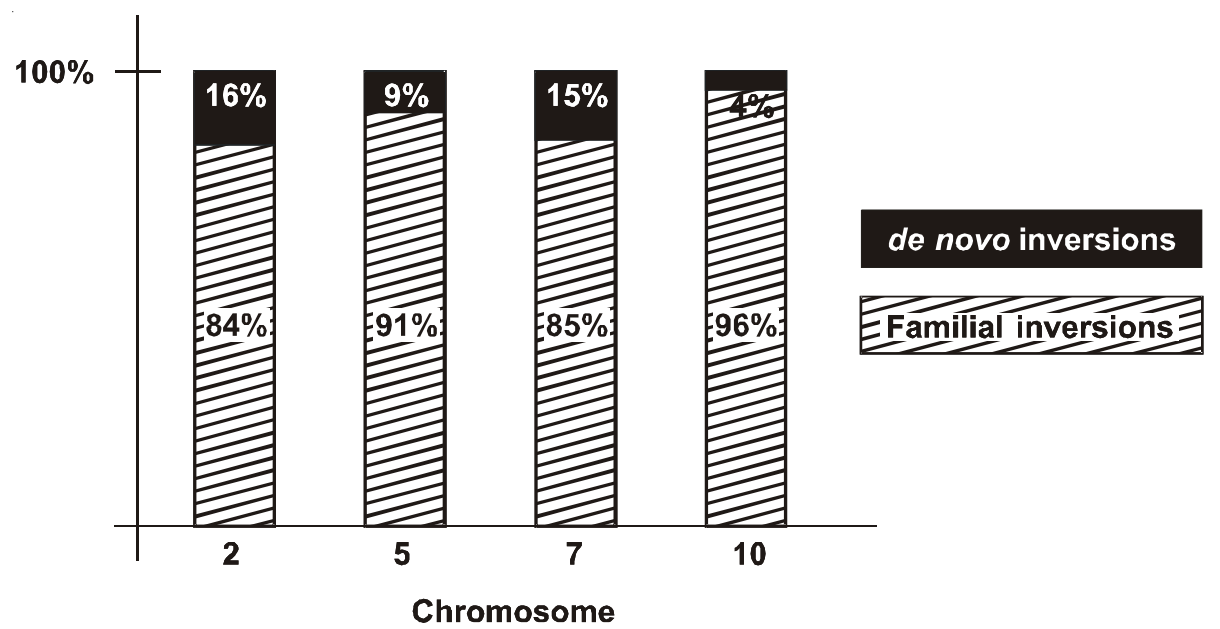

Fig. 1. Frequency and origin of inversions of the chromosomes 2, 5, 7 and 10 (summary according to Borgaonkar, 1997).

inversions analysed in the context of diagnostic processes), familial cases also dominated, just as in the studies discussed above. In all, $72 \%$ of our cases were familial in origin, while $28 \%$ originated de novo in the parent. $58 \%$ of the familial cases were of maternal and $42 \%$ were of paternal origin.

A similar classification was not possible for inversions of the heterochromatin.

There is no published documentation for all the various structural aberrations (dup, del, ins, $r$, rcp), only descriptions of specific cases (Borgaonkar 1997), so that inversions can not in analysed in comparison to these.

\section{INTERCHROMOSOMAL DISTRIBUTION OF INVERSIONS}

\section{Rearrangements within the Euchromatin}

Inversions have been analysed in different frequencies according to the investigating group (0.12-5.25\%o). In our own patient collective (91 inversions among 41,000 diagnostic cases) we found a frequency of $2.24 \%$. Of these, $60 \%$ were pericentric and $40 \%$ were paracentric inversions, which is in accordance with the differences in the other populations studied.

\section{Pericentric Inversions}

Pericentric inversions have been described for all chromosomes, and with a frequency of $0.5 \%$, they are among the less common structural aberrations in humans. However, their incidence differs strongly from chromosome to chromosome.

The authors of the French collaborative study (1986a) analysed a total of 305 independent cases.

The most common inversions within this collective were rearrangements of chromosomes 2, 10 (two different types), 5 and 7.

$\operatorname{Inv}(2)(\mathrm{p} 12 \mathrm{q} 14.1)$ is most common in all groups studied, and homozygosity for this rearrangement seems to be innocuous (Gelman-Kohan et al. 1993; Schmidt et al. 2005). This lack of an effect for the carrier is apparently quite widespread, as there are no pairing difficulties in meiosis I and thus no unequal crossing-over.

Our own investigation group showed comparable results. Chromosomes 2,10 and the $\mathrm{Y}$ chromosome most frequently had pericentric inversions.

Inversions in chromosomes 1,8 and 16, however, are rare. The French study did not find an inv(16). Borgaonkar, on the other hand, mentions one (1997). A possible reason for such rare findings may be unequal recombination causing lethality and thus, limited detection. Furthermore, a position effect may explain the infrequent occurrence of certain inversions, as indicated by the incidence of $\operatorname{inv}(16)$ in some leukaemia cells (ANLL-M2, -M4) (Golomb et al. 1978).

Gardner and Sutherland (2004) list further frequent inversions, such as inv(3)(p11q12); $\operatorname{inv}(3)(\mathrm{p} 13 \mathrm{q} 12)$; inv(5)(p13q13) and inv(10) (p11.2q21.2). In this context it is important to 
consider that break points cannot always be determined precisely. Thus, inexact localisations and publications that appear to describe different inversions result when in fact only one rearrangement exists.

The authors of the French collaborative study identified 118 different inversion regions. A certain variance in the incidences depending on the population surveyed is apparent. Furthermore, there is a discrepancy between the values found for different age groups. Thus, pericentric inversions are found in 10 out of 70613 newborns $(0.14 \%$ ) (Nielsen et al. 1982) and 3 out of 5488 newborns (0.6\%o) (Hansteen et al. 1982), respectively, while in older individuals, the percentages are significantly higher, ranging from $0.3 \%$ o to $5 \%$, which corresponds to an average of $1.4 \%$ (discounting relatives of the probands) or $2.6 \%$ including relatives. The lower incidence found for newborns as compared to the inversion rate in older probands is most probably due to methodical differences in the authors' analyses. The average frequency of pericentric inversions is estimated to be about $0.5 \%$.

As early as 1983, Teyssier and Moreau drew a comparison between inversion rates in a series of newborns and those in a collective of subfertile persons. They found that the latter group showed a six fold higher incidence of inversions, which they attributed to exaggerated numbers in the subfertile collective.

The causes for differing inversion frequencies in various chromosomes remain unknown to date; however, reproductive disadvantages due to the occurrence of unbalanced karyotypes may be an issue.

The interchromosomal distribution of inversions showed discrepant frequencies in the individual studies. A summary of relevant publications identified inv(2)(p12q14) as the most common inversion, just as the French collaborative study did (Ait-Allah et al. 1997; Schmidt et al. 2005). Kaiser's second most common rearrangement, however, was inv(8) (p23q22) (Kaiser 1984), which the authors of the French study did not find at all. Conversely, the French authors identified $\operatorname{inv}(5)(\mathrm{p} 14 \mathrm{q} 14) 22$ times, whereas Kaiser found it only once.

\section{Paracentric Inversions}

The $0.25 \%$ incidence which is often given for paracentric inversions (Pettenati et al. 1995) corresponds to approximately half the value found for pericentric inversions. This frequency probably reflects realistic distributions more accurately than those specified by the authors of the French study (1986b), who found a tenfold higher incidence of pericentric inversions as compared to paracentric inversions.

Modern molecular-cytogenetic methods such as FISH are capable of detecting even very small paracentric inversions which previously escaped notice. Furthermore, in contrast to pericentric inversions, paracentric inversions only rarely cause physical abnormalities in offspring, which precludes an important indicator often leading to detection. Larger, microscopically visible paracentric inversions do occur in almost every single chromosome; however, they are considerably less common than pericentric inversions of the same magnitude.

The French group of researchers postulated that the incidence of paracentric inversions is proportional to the length of the chromosome arms. However, this hypothesis has not been confirmed by recent findings. This study demonstrated a correlation between frequency and total length of the chromosomes, but it also showed that, given the total lengths are the same, more paracentric inversions exist for non-metacentric than for metacentric chromosomes. Thus, the actual distribution of the identified inversions was not reflected in the theoretically expected values. Paracentric inversions were most often found for chromosomes 3, 7, 11, 1 and 5. In individual chromosomes up to five different areas were affected. Detection difficulties alone cannot explain the differences found for the various chromosomes (French Study 1986b); differing geographical distributions may also play a role.

Data from other publications confirm the inversion frequencies found in the French study. A particularly conspicuous observation made by all authors is that chromosome 2 does not appear to accomadate paracentric inversions, in contrast to pericentric inversions, which occur most often on chromosome 2.

Within our own investigation group chromosome 11 showed the highest number of paracentric inversions, followed by chromosomes 6 and 7 .

Total Distribution of Euchromatic Inversions and Comparison of Minima and Maxima for Pericentric and Paracentric Rearrangements

The incidence of pericentric and paracentric inversions differs for the various chromosomes. 
The most common pericentric inversions are $\operatorname{inv}(2)(28.53 \%), \operatorname{inv}(10)(9.51 \%), \operatorname{inv}(5)(7.21 \%)$ and $\operatorname{inv}(7)(3.11 \%)$. The most common paracentric inversions are inv(3) (18.46\%), inv(7) (16.92\%), $\operatorname{inv}(11)(10.77 \%), \operatorname{inv}(1)(9.23 \%)$ and $\operatorname{inv}(5)$ (7.69\%).

The most common inversion for both types affects a chromosome from the A group, namely chromosome 2 for pericentric inversions and chromosome 3 for paracentric inversions. A further noteworthy observation is that chromosomes 5 and 7 are among the four most common pericentric and the five most common paracentric inversions. There are neither acrocentrics nor sex chromosomes among the most commonly affected chromosomes.

Pericentric inversions have been identified for all chromosomes. However, inv(1), inv(8) and inv(16) occur very rarely. In addition to the chromosomes specified above, a list of frequent inversions should include the following: inv(3)(p11q12); inv(3)(p13q12); inv(5)(p13q13); inv(10)(p11.2q21.2). The total incidence of pericentric inversions is estimated to be approximately 0.12 to $0.7 \%$ (Pettenati et al. 1995).

Paracentric inversions have also been found for all chromosomes. The total incidence of paracentric inversions is estimated to be approximately $0.25 \%$ and thus about half as high as the rate for pericentric inversions.

\section{Interchromosomal Distribution of Heterochromatic Inversions}

In a study carried out by Kalz (2003) characterizing pericentric inversions of the heterochromatin in a collective comprising 817 probands, the most common inversion by far was located in chromosome segment 4q11.2 (15.18\%). The next most commonly affected region was in $3 q 11.2$ (2.45\%), followed by $9 q 12$ (1.96\%), Yq12 $(0.25 \%)$ and $1 q 12(0.12 \%)$. No inversions were found in 16q11.2. These values demonstrate that there is no correlation between the relative length of the heterochromatic segment (in relation to the total length of the chromosome) and the inversion frequency.

\section{Comparison of the Interchromosomal Distribution of Euchromatic and Heterochromatic Inversions}

In contrast to euchromatic inversions, heterochromatic inversions are confined to a small number of chromosomes (1,3,4,9,16 and Y) and occur only in a strictly defined segment of these chromosomes.

Euchromatic inversions, on the other hand, have been identified in all chromosomes and are not confined to a specific segment. However, certain breakpoints occur preferentially in both euchromatic and heterochromatic inversions (see below).

\section{INTRACHROMOSOMAL DISTRIBUTION OF A BERRATIONS WITH SPECIAL REGARD TO MUTATION HOTSPOTS}

\section{Euchromatic Inversion Breakpoints}

The researchers participating in the French collaborative study (1986b) found a distinct preference for certain intrachromosomal breakpoints. This tendency was particularly pronounced for chromosomes 3 and 7, and breakpoint maxima were also found for chromosomes 14 and 11. However, there are some differences in the inversion incidence given for individual chromosomes.

\section{Pericentric Inversions}

Some pericentric breakpoints occur preferentially in certain chromosome regions. Bands $2 \mathrm{p} 13$, 2q21, 5q13, 5q31, 6q21, 10q22 and 12q13 are striking examples for this preference (Kleczkowska et al. 1987). Regions such as these, which are more frequently subject to mutation than others, are termed hotspots. In each case the hotspots consist of an extensive GC-rich band.

Kaiser found a number of preferred breakpoint regions in chromosomes 1-6, 8-13, 18 as well as X and $\mathrm{Y}$ which differ from those given above.

The differing frequencies of certain inversions in the various publications may be due to differences in the size of the collectives.

\section{Paracentric Inversions}

As is the case for pericentric inversions, there are certain preferred breakpoints for paracentric inversions, too (Price et al. 1987; Hales et al. 1993; Estop et al. 1994). The most frequent mutations have breakpoints in 3p24 and 3p26, in 7q22 and in $11 \mathrm{q} 12$ and $11 \mathrm{q} 22$. The breakpoints in $3 \mathrm{p} 24$, 3 p26 and 11q22 lie within large AT-rich bands, while those in 7q22 and 11q12 are located in large GC-rich bands.

In a study published by Madan in 1995, 38 of 
184 examined inversions had breakpoints in 11q, and of these, 31 breakpoints were located in 11q21-q23. 24 of these 184 inversions had breakpoints in $7 \mathrm{q} 22$.

\section{Heterochromatic Inversion Breakpoints}

Partial and complete pericentric inversions occur in the following regions: $1 \mathrm{q} 12,3 \mathrm{q} 11.2$, $4 q 11.2,9 q 12,16 q 11.2$. Inversions involving $4 q 11.2,3 q 11.2$ and $9 q 12$ are frequent, as compared to the less frequent breakpoint in 16q11.2. Breakpoints in the short arm are found at the border between the pericentromeric heterochromatin in p11.1 and the distally located euchromatin in $\mathrm{p} 12$. In the long arm, there are usually two possible breakpoints: one within the heterochromatin block at the border between the two subunits (resulting in a partial inversion), and one at the border between the heterochromatin block and the distally adjoining euchromatin. Inversions occur in the Y chromosome also, as mentioned above; however, in these inversions, usually the entire heterochromatin block is exchanged (Kalz 2003).

\section{Comparison of the Distribution of Preferred Breakpoints in Euchromatic and Heterochromatic Inversions}

In the various euchromatic inversion types, the average length of the inverted segment in relation to the entire chromosome amounts to approximately one third (32\%) as compared to an average length of $9 \%$ for heterochromatic inversions.

\section{Cryptic Inversions}

Inversions which are not detectable through karyotype analysis may be identified through molecular cytogenetic techniques. Cryptic inversions smaller than $10 \mathrm{MB}$ are apparently quite common and may be the cause of malformation/retardation syndromes. A recent study demons-trated the existence of a genomic rearrangement in 7q11.23, more specifically a submicroscopic inversion, in a number of parents whose children were diagnosed as having Williams-Beuren syndrome (WBS) (Osborne et al. 2001). These patients had acquired a microdeletion that was traced to disturbed pairing of the altered parental chromosomes.
Interphase FISH and analysis of prometaphase chromosomes have shown that in approximately $33 \%$ one parent was heterozygous for a $1.5 \mathrm{Mb}$ paracentric inversion covering the entirety of the Williams-Beuren region. Hetero-zygosity for this inversion causes unequal chromosome pairing in prophase of meiosis I, which may consequently lead to deletion of the critical region.

Bayés et al. (2003) documented the mode of inheritance for the rearranged chromosome 7 . In all informative cases the deletion had occurred de novo in the child. In $45 \%$ of cases the inverted chromosome was maternal, in $55 \%$ of cases it was paternal.

\section{ARTIFICIAL INVERSIONS AS A METHOD IN GENE MAPPING AND ANALYSIS OF GENE FUNCTION}

Many new methods have been developed in recent years to facilitate the analysis of the genome. Many of these are of particular importance in the study of model organisms. The unspecific und non-selective induction of mutations in mice using chemical mutagens and the time-consuming screening of the many resulting mutations has proven to be too laborious. The induction of a specific deletion on a certain chromosome as a first step of a research series also proved to be ineffective, as the majority of mutations turned out to be lethal even in the heterozygous state. Thus, a different approach using balanced inversions was conceived (Kile et al. 2003). One main focus of attention was chromosome 11 in the mouse model, which corresponds to chromosome 17 in man. The inversion these researchers induced comprised approximately $2 \%$ of the total length of the genome and contained about 700 genes. Identification of inversion carriers was made possible through the secondary integration into the inverted region of a gene for yellow fur colour. These inversion mice were bred with mice that had been subjected to a chemical mutagen (ENU), resulting in different mutations in various locations in the genome. Backcrossing and additional analysis of lethal effects for the various embryonic stages allowed researchers to identify different mutations for the inverted region (Rossant 2003). 


\section{SIGNIFICANCE OF INVERSIONS FOR THE EVOLUTION OF THE HUMAN KARYOTYPE}

Comparative chromosome and genome analyses have demonstrated a considerable degree of conformity among primates. However, there are significant morphological differences between the karyotypes of the three large ape species and that of humans (Szamalek et al. 2006). These differences are, for the most part, a result of intrachromosomal rearrangements and a telomeric fusion. Pericentric inversions are the most frequent rearrangement, while paracentric inversions are considerably less common.

The occurrence of pericentric inversions within a species resulted in genetic stability, as soon as homozygosity was achieved.

Analysis of the primate karyotype clearly shows that various euchromatic inversions were disseminated throughout populations in the past, which means that they obviously were not associated with significantly reduced fertility of the carriers.

Morphological karyotype differences between Homo sapiens and chimpanzees (Pan troglodytes) include three pericentric inversions. Five pericentric inversions exist between Homo sapiens and gorillas (Gorilla gorilla), and five pericentric and one paracentric inversion between Homo sapiens and orang-utans (Pongo pygmaeus). These rearrangements in the euchromatin are accompanied by pericentric inversions in the constitutive heterochromatin (Seuánez 1979).

The breakpoints defining of the most frequent inversions, on chromosome 2 , are located in a region that was quite significant in the evolution process of the human karyotype, as human chromosome 2 resulted from the fusion of two acrocentric ancestral chromosomes. The paracentric inversion involving 7(q11q22) occurs in both humans and gorillas, and is found exclusively in phenotypically inconspicuous individuals. This indicates a stable rearrangement of the genome. It is interesting to note that this inversion results in the same banding pattern in man and in the gorilla (Haaf and Schmid 1987).

\section{SUMMARY}

A review of published literature and our own research data provide the basis for the charac- terization of inversions as a group of intrachromosomal aberrations. Heterochromatic and euchromatic inversions are compared, and for the latter group, rearrangements of the autosomes and sex chromosomes are considered separately. Pericentric and paracentric inversions as defined by the position of the inversion within the chromosome are discussed. Specific features of meiosis as well as genetic risks are reviewed in the context of various inversion types. The ascertainment of frequencies for pericentric and paracentric inversions in general and for specific chromosomes is discussed on the basis of the results of several studies. Hotspots for inversion breakpoints and cryptic inversions are charac-terized. The role of inversions during the process of the evolution of the human karyotype is demonstrated.

\section{REFERENCES}

Ait-Allah A, Ming P, Salem H, Reese E 1997. The clinical importance of pericentric inversions of chromosome 9 in prenatal diagnosis. J Matern Fetal Invest, 7: $126-128$.

Anton E, Blanco J, Egozcue J, Vidal F 2005. Sperm studies in heterozygote inversion carriers: A review. Cytogenet Genome Res, 111: 297-304.

Ayukawa H, Tsukahara M, Fukuda M, Kondoh O 1994. Recombinant chromosome 18 resulting from a maternal pericentric inversion. Am J Med Genet, 50: 323-325

Balicek P 2001. Pericentric inversion of human chromosomes and its risks. Cas Lek Cesk, 140: 38-42.

Balicek P 2004. Paracentric inversions of human chromosomes and their risks. Cas Lek Cesk, 143: 35-38.

Bayés M, Magano LF, Rivera N, Flores R, Pérez Jurado LA 2003. Mutational mechanisms of WilliamsBeuren syndrome deletions. Am J Hum Genet, 73: 131-151.

Bocian E, Suchenek K, Obersztyn E, Nowakowska B, Mazurczak T 2005. Recombination aneusomy of subtelomeric regions of chromosome 5 , resulting from a large familial pericentric inversion inv(5)(p15.33q35.3). J Appl Genet, 46: 109-114.

Borgaonkar DS 1997. Chromosomal Variation in Man. A Catalog of Chromosomal Variants and Anomalies. New York: Wiley-Liss, Inc.

Boué A, Gallano P 1984. A collaborative study of the segregation of inherited chromosom structural rearrangements in 1356 prenatal diagnoses. Prenat Diagn, 4: 45-67

Daniel A 1981. Structural differences in pericentric imversions. Application to a model of risk of recombinants. Hum Genet, 56: 321-328.

Daniel A, Hook EB, Wulf G 1989. Risks of unbalanced progeny at amniocentesis to carriers of chromosome rearrangements: data from United States and Canadian laboratories. Am J Med Genet, 31: 14-53. 
de Grouchy J, Turleau C 1982. Atlas des maladies chromosomiques. Paris: Expansion scientifique française.

Devine DH, Whitman-Elia G, Best RG, Edwards JG 2000. Parental paracentric inversion of chromosome 2: a possible association with recurrent pregnancy loss and infertility. J Assist Reprod Genet, 17: 293-296.

Duckett DP, Young ID 1988. A recombinant X chromosome in a short statured girl resulting from a maternal pericentric inversion. Hum Genet, 79: 251-254.

Dutrillaux B, Laurent C, Robert JM, Lejeune J 1973. Inversion péricentrique, inv(10), chez la mère et aneusomie de recombinaison, $\operatorname{inv}(10), \operatorname{rec}(10)$, chez son fils. Cytogenet Cell Genet, 12: 245-253.

Dutrillaux B, Aurias A, Viegas-Pequignot E 1980. Modifications chromosomiques dans l'évolution et en pathologie: analyse des inversions péricentriques. C R Soc Biol, 174: 730-740.

Dutrillaux B, Rotman J, Gueguen J 1982. Chromosomal factors in the infertile male. In: Vere White de (Ed) International Aspects of Male Infertility, vol 4. Baltimore London: Williams \& Wilkins, pp. 89-109.

Engel E, Antonarakis SE 2002. Genomic Imprinting and Uniparental Disomy in Medicine. Clinical and Molecular Aspects. New York: Wiley-Liss, Inc.

Estop AM, Bansal V, Lin A, Levinson F, Karlin SM, Surti U, Wenger SL, Steele MW 1994. Three unrelated cases of paracentric inversions of $1 \mathrm{p}$ in individuals with abnormal phenotypes. Am J Med Genet, 49: 410-413.

Fraisse J, Philip T, Bertheas MF, Laurs B 1986. Six cases of partial duplication-deficiency 21 syndrome: 21(dup(q22)del(p23)) due to maternal pericentric inversion $\operatorname{inv}(21)(\mathrm{p} 12 ; \mathrm{q} 22)$. A familial study. Ann Génét, 29: 177-180.

Gabriel-Robez O, Rumpler Y 1994. The meiotic pairing behaviour in human spermatocytes carrier of chromosome anomalies and their repercussions on reproductive fitness. I. Inversions and insertions. A European collaborative study. Ann Génét, 37: 3-10.

Garcia-Heras J, Martin J 2002. A rec(4) dup 4p inherited from a maternal $\operatorname{inv}(4)(\mathrm{p} 15 \mathrm{q} 35)$ : case report and review. Am J Med Genet, 109: 226-230.

Gardner RJM, Sutherland GR 2004. Chromosome Abnormalities and Genetic Counseling ( ${ }^{\mathrm{rd}}$ Ed.). Oxford Monographs on Medical Genetics 46. New York Oxford: Oxford University Press.

Gelman-Kohan Z, Rosensaft J, Ben-Cohen RN, Chemke J 1993. Homozygosity for inversion (2)(p12q14). Hum Genet, 92: 427.

Gersen SL, Keagle MB 1999. The Principles of Clinical Cytogenetics. Totowa, New Jersey: Humana Press.

Giraldo A, Silva E, Martinez I, Campos C, Guzman J 1981. Pericentric inversion of chromosome 1 in three sterile brothers. Hum Genet, 58: 226-227.

Golomb HM, Vardiman JW, Rowley JD, Testa JR, Mintz U 1978. Correlation of clinical findings with quinacrine-banded chromosomes in 90 adults with acute nonlymphocytic leukaemia: an eight-year study (1970-1977). N Engl J Med, 299: 613-619.

Gosden JR, Spowart G, Lawrie SS 1981. Satellite DNA and cytological staining patterns in heterochromatic inversions of human chromosome 9. Hum Genet, 58: $276-278$.
Groupe de Cytogénéticiens Français 1986a: Pericentric Inversions in man. A French collaborative study. Ann Génét, 29: 129-168.

Groupe de Cytogénéticiens Français 1986b: Paracentric inversions in man. A French collaborative study. Ann Génét, 29: 169-176.

Haaf Haaf T, Schmid M 1987. Chromosome heteromorphisms in the gorilla karyotype. Analyses with distamycin A/DAPI, quinacrine and 5azacytidine. $J$ Hered 78: 287-92.

Hales HA, Peterson CM, Carey J, Hecht BK, Hecht F 1993. Prenatal detection of de novo paracentric inversion 46, XX inv (14) (q22q32.1) in a normal child: report and review of the literature. Am J Med Genet 47: 848-51.

Hansteen IL, Varslot K, Steen-Johnsen J, Langard S 1982. Cytogenetic screening of a new-born population. Clin Genet 21: 309-14.

Herva R, de la Chapelle A 1976. A large pericentric inversion of human chromosome 8. Am J Hum Genet, 28: 208-212.

Iselius L, Sherman S, Gallano P, Buckton K, Collyer S, Demey R, Kristofferson U, Lindsten J, Mikkelsen M, Morton N, Newton M, Nordensson I, Petersen M, Wahlstrom J 1985. Segregation analysis of balanced pericentric inversions in pedigree data. $\mathrm{Am}$ J Hum Genet, 37 Suppl: A98.

Jacobs PA, Frackiewicz A, Hilditch CJ, Morton NE 1975. The effect of structural aberrations of the chromosomes on reproductive fitness in man. Clin Genet, 8: 169-178.

Jenderny J, Gebauer J, Röhrborn G, Rüger A 1992. Sperm chromosome analysis of a man heterozygous for a pericentric inversion of chromosome 20. Hum Genet, 89: 117-119.

Kaiser P 1984. Pericentric Inversions. Problems and significance for clinical genetics. Hum Genet, 68 : 1-47.

Kaiser P 1988. Pericentric Inversions: their problems and clinical significance. In: A Daniel (Ed.) The Cytogenetics of Mammalian Autosomal Rearrangements. New York: Alan R. Liss. pp. 163-247.

Kalz L 2003. Chromosomenpolymorphismen des konstitutiven Heterochromatins im Karyotyp des Menschen. Untersuchungen zu ihrer Häufigkeit und zur Mutationsfrequenz der verschiedenen Regionen unter Berück-sichtigung der ethnischen Herkunft. Aachen: Shaker.

Kalz L, Schwanitz G 2004. Characterization of constitutive heterochromatin, in particular of fluorescence polymorphisms in a Central European population. Int J Hum Genet, 4:1-10.

Keitges EA, Palmer CG, Weaver DD 1982. Pericentric $\mathrm{X}$ inversion in dizygotic twins who differ in $\mathrm{X}$ chromosome inactivation and mensual cycle function. Hum Genet, 62: 210-213.

Kile BT, Hentges KE, Clark AT, Nakamura H, Salinger AP, Liu B, Box N, Stockton DW, Johnson RL, Behringer RR, Bradley A, Justice MJ 2003. Functional genetic analysis of mouse chromosome 11. Nature 425: 81-6.

Kleczkowska A, Fryns JP, Van den Berghe H 1987. Pericentric inversions in man: personal experience and review of literature. Hum Genet, 75: 333-338.

Koehler KE, Millie EA, Cherry JP, Schrump SE, Hassold 
TJ 2004. Meiotic exchange and segregation in female mice heterozygous for paracentric inversions. Genetics 166: 1199-214.

Lejeune J 1963. Autosomal disorders. Pediatrics, 32: 326-337.

Léonard C, Gautier M, Sinet PM, Selva J, Huret JL 1986. Two Down syndrome patients with $\operatorname{rec}(21), \operatorname{dup}(q)$, inv(21)(p11;q2109) from a familial pericentric inversion. Ann Génét, 29: 181-183.

Madan K 1988. Paracentric inversions and their clinical implications. In: A. Daniel (Ed.) The Cytogenetics of Mammalian Autosomal Rearrangements. New York: Alan R. Liss. pp. 249-266.

Madan K 1995. Paracentric inversions: a review. Hum Genet, 96: 503-15

Madan K, Nieuwint AW 2002. Reproductive risks for paracentric inversion heterozygotes: Inversion or insertion? That is the question. Am J Med Genet, 107(4): 340-343.

Martin RH 1986. Sperm chromosome analysis in a man heterozygous for a paracentric inversion of chromosome 7 (q11q22). Hum Genet, 73: 97-100.

Martin RH 1988. Abnormal spermatozoa in human translocation and inversion carriers. In: A. Daniel (Ed.) The cytogenetics of mammalian autosomal rearrangements. New York: Alan R. Liss. pp. 397-417.

Martin RH, Ko E, Rademaker A 1991. Distribution of aneuploidy in human gametes: comparison between human sperm and oocytes. Am J Med Genet, 39: 321-331.

Martin RH 1993. Analysis of sperm chromosome complements from a man heterozygous for a pericentric inversion, inv(8)(p23q22). Cytogenet Cell Genet, 62: 199-202.

Martin RH, Rademaker A, German J 1994. Chromosomal breakage in human spermatozoa, a heterozygous effect of the Bloom syndrome mutation. Am J Hum Genet, 55: 1242-1246.

Mattei MG, Mattei JF, Guichaoua M, Giraud F 1981. Partial Inversion of the secondary constriction of chromosome 9. Does it exist? Hum Genet, 59: 310316.

Meschede D, Froster UG, Bergmann M, Nieschlag E 1994. Familial pericentric inversion of chromosome 1 (p34q23) and male infertility with stage specific spermatogenic arrest. J Med Genet, 31: 573-575.

Miller OJ, Therman E 2001. Human Chromosomes $\left(4^{\text {th }}\right.$ Ed.) New York, Berlin, Heidelberg: Springer.

Morton NE, Jacobs PA, Frackewicz A, Law P, Hilditch CJ 1975. The effect of structural aberrations of the chromosomes on reproductive fitness in man. Clin Genet, 8: 159-168

Mules EH, Stamberg J 1984. Reproductive outcomes of paracentric inversion carriers. Report of a liveborn dicentric recombinant and literature review. Hum Genet, 67: 126-131.

Navarro J, Benet J, Martorell MR, Templado C, Egozcue J 1993. Segregation analysis in a man heterozygous for a pericentric inversion of chromosome 7(p13q36) by sperm chromosome studies. Am J Hum Genet, 53: 214-219.

Neu RL, Brar HS, Koos BJ 1988. Prenatal diagnosis of $\operatorname{inv}(\mathrm{X})(\mathrm{q} 12 \mathrm{q} 28)$ in a male fetus. J Med Genet, 25: $52-53$.

Nielsen J, Wohlert M, Faaborg-Andersen J, Hansen KB,
Hvidman L, Krag-Olsen B, Moulvad I, Videbech P 1982. Incidence of chromosome abnormalities in newborn children. Comparison between incidences in 1969-1974 and 1980-1982 in the same area. Hum Genet, 61: 98-101.

Osborne LR, Martin L, Pober B, Chitayat D, Bodurtha J, Mandel A, Costa T, Grebe T, Cox S, Tsui L-C, Scherer SW 2001. A 1.5 million-base pair inversion polymorphism in families with Williams-Beuren syndrome. Nat Genet, 29: 321-325.

Pai GS, Shields SM, Houser PM 1987. Segregation of inverted chromosome 13 in families ascertained through liveborn recombinant offspring. Am J Med Genet, 27: 127-133.

Pettenati MJ, Rao PN, Phelan MC, Grass F, Smith JL, Higgins MD, Lanman JT, Higgins RR, Butler MG, Luthardt F, Keitges E, Jackson-Cook C, Brown J, Schwartz S, Van Dyke DL, Palmer CG 1995. Paracentric inversions in humans: a review of 446 paracentric inversions with presentation of 120 new cases. Am J Med Genet, 55: 171-187.

Price HA, Roberts SH, Laurence KM 1987. Homozygous paracentric inversion 12 in a mentally retarded boy: a case report and review of the literature. Hum Genet, 75: 101-108.

Rivas F, García-Esquivel L, Rivera H, Jiménez ME, González RM, Cantú JM 1987. Inv(4)(p16q21). A five-generation pedigree with 24 carriers and no recombinants. Clin Genet, 31: 97-101.

Roberts P, Williams J, Sills MA 1989. A case of two inversion (10) recombinants in a family. J Med Genet, 26: 461-464.

Romain DR, Columbano-Green LM, Whyte S, Smythe RH, Parfitt RG, Gebbie OB, Chapman CJ 1983. Familial paracentric inversion of 1p. Am J Med Genet, 14: 629.

Rossant J 2003. Genetics: A balancing act. Nature, 425 : 29-32.

Saura R, Longy M, Sautarel M, Renouil M, Sandler B 1983. Double trisomie et inversion péricentrique transmise $[48, X X Y,+21$ inv(22)]. Effet interchromosomique. Ann Génét, 26: 180-182.

Scherer SW, Gripp KW, Lucena J, Nicholson L, Bonnefont JP, Perez-Jurado LA, Osborne LR 2005. Observation of a parental inversion variant in a rare Williams-Beuren syndrome family with two affected children. Hum Genet, 117(4): 383-388.

Schmidt S, Claussen U, Liehr T, Weise A 2005. Evolution versus constitution: differences in chromosomal inversion. Hum Genet, 117: 213-219.

Schorderet DF, Friedman C, Disteche CM 1991. Pericentric inversion of the $\mathrm{X}$-chromosome: presentation of a case and review of the literature. Ann Génét, 34: 98-103.

Seuánez HN 1979. The Phylogeny of Human Chromosomes. New York, Berlin, Heidelberg: Springer.

Smith AC, Spuhler K, Williams TM, McConnell T, Sujansky E, Robinson A 1987. Genetic risk for recombinant 8 syndrome and the transmission rate of balanced inversion 8 in the Hispanic population of the southwestern United States. Am J Hum Genet, 41: 1083-1103.

Stene J 1986. Comments on methods and results in: Sherman et al. "Segregation analysis of balanced pericentric inversions in pedigree data." Clin Genet, 30: $95-107$. 
Sturtevant AH 1926. A crossover reducer in Drosophila melanogaster due to inversion of a section of the third chromosome. Biol Zentralbl, 46: 697-702.

Sutherland GR, Gardiner AJ, Carter RF 1976. Familial pericentric inversion of chromosome 19, inv(19) (p13q13) with a note on genetic counselling of pericentric inversion carriers. Clin Genet, 10: 54-59.

Szamalek JM, Cooper DN, Schempp W, Minich P, Kohn M, Hoegel J, Goidts V, Hameister H, KehrerSawatzki H 2006. Polymorphic micro-inversions contribute to the genomic variability of humans and chimpanzees. Hum Genet, 119: 103-112.

Talaban R, Sellick GS, Spendlove HE, Howell R, King C, Reckless J, Newbury-Ecob R, Houlston RS 2005. Inherited pericentric inversion $(X)(p 11.4 q 11.2)$ associated with delayed puberty and obesity in two brothers. Cytogenet Genome Res, 109: 480-484.

Teyssier M, Moreau N 1983. Inversion péricentrique familiale du chromosome 10. Deux nouveau cas. Ann Génét, 26: 183-186.

Therman E, Laxova R, Susman B 1990. The critical region on the human Xq. Hum Genet, 85: 455-461.

Tóth A, Gaál M, László J 1984. Familial pericentric inversion of the Y-Chromosome. Ann Génét, 27: 60-61.

Valero MC, de Luis O, Cruces J, Pérez Jurado LA 2000.
Fine-scale comparative mapping of the human $7 q 11.23$ region and the orthologous region on mouse chromosome 5G: the low-copy repeats that flank the Williams-Beuren syndrome deletion arose at break-point sites of an evolutionary inversion(s). Genomics, 69: 1-13.

Venter PA, Dawson B, Du Toit JL, Smith EL, Kritzinger N, Landman S, Cronje AS, Hof JO 1984. A familial paracentric inversion: a short review of the current status. Hum Genet, 67: 121-125.

Verma RS, Rodriguez J, Dosik H 1982. The clinical significance of pericentric inversion of the human Y chromosome: A rare "third" type of heteromorphism. J Hered, 73: 236-238.

Voiculescu I, Barbi G, Wolff G, Steinbach P, Back E, Schempp W 1986. Familial pericentric inversion of chromosome 12. Hum Genet, 72: 320-322.

Winsor EJT, Palmer CG, Ellis PM, Hunter JLP, FergusonSmith MA 1978. Meiotic analysis of a pericentric inversion, inv(7)(p22q32), in the father of a child with a duplication-deletion of chromosome 7 . Cytogenet Cell Genet, 20: 169-184.

Wyandt HE, Tonk VS (Eds.) 2004. Atlas of Human Chromosome Heteromorphisms. Dordrecht, Boston, London: Kluwer Academic Publishers. 